\title{
A Bossa Nova e a influência do blues, 1955-1964*
}

\section{Bryan McCann ${ }^{* *}$}

Este artigo considera as conexões entre blues e bossa nova, pouco reconhecidas na literatura sobre bossa nova mas muito importantes para o desenvolvimento do estilo. Analisando as gravações do circuito samba-jazz em Copacabana nas décadas de 1950 e 1960, o artigo traz à luz uma prática de blues, tanto na estrutura de doze compassos como na utilização da escala blues como matéria de improviso, bastante comum naquela época. O artigo explica o papel de figuras-chaves como Booker Pittman, Moacir Santos e Paulo Moura na transmissão de uma influência do blues no Rio de Janeiro e os efeitos dessa influência na bossa nova.

Palavras-chave: Blues - Bossa Nova - Samba-Jazz

\section{The influence on the Bossa Nova of the blues, 1955-1964}

This article considers the connections between the blues and the bossa nova, which have been little recognized in the literature on bossa nova, but was of great importance for the genre's development. Through analysis of recordings made on the Copacabana samba-jazz circuit of the 1950 s and '60s, this article brings to light a blues-based practice, both in the use of a twelve-bar structure and in the use of the blues scale as a basis for bossa nova improvisation. The article also explains the importance of key figures like Booker Pittman, Moacir Santos and Paulo Moura in the transmission of blues influence in Rio de Janeiro, and the effects of this influence on the subsequent development of bossa nova.

Keywords: Blues - Bossa Nova - Samba-Jazz

\footnotetext{
* Artigo recebido e aprovado para publicação em julho de 2009.

*** Departamento de História da Georgetown University. E-mail: bm85@georgetown.edu
} 


\section{La Bossa Nova et l'influence des blues, 1955-1964}

Le présent article étudie les liens entre les «blues» et la «bossa nova», peu mentionnés et reconnus dans la littérature sur ce genre, mais qui ont été très importants pour le développement du style. En analysant les enregistrements du circuit samba-jazz à Copacabana au cours des années 1950 et 1960, l'article met en lumière la pratique des blues, aussi bien en ce qui touche la structure de douze mesures comme l'utilisation de la gamme des blues, en improvisation, modalité assez commune à l'époque. L'article explique le rôle de personnages-clés comme Booker Pittman, Moacir Santos et Paulo Moira dans la transmission d'une influence des blues à Rio de Janeiro, et les retombées de cette influence sur la Bossa Nova.

Mots-clés : Blues - Bossa Nova - Samba-Jazz

The Jaz: ' $n$ ' samba, the jaz: 'n' samba, hear it all aroundl The jazs 'n' samba, the jaz: 'n' samba sound. ("O Jazz no samba, o jazz no samba, a gente ouve em toda a parte/ O jazz no samba, o som do jazz no samba”). Esta é a letra em inglês de Norman Gimbel para a canção de bossa nova do Tom Jobim "Só Danço Samba", letra original de Vinicius de Moraes. Como em muitos casos, a versão em inglês pega o ritmo e poesia da letra original e a transforma em bobagem. Deixando isso de lado por um instante, a letra de Gimbel resume de maneira concisa a compreensão comum das origens da bossa nova - os tons e estilo improvisados do jazz unidos ao ritmo de samba produzem algo novo e contagiante. Essa compreensão, já prevalente quando Gimbel escreveu essas palavras no início dos anos 60 , continua a servir como base para a maioria das interpretações da bossa nova. Tudo bem, até certo ponto, isso é incontestável, mas também não muito interessante.

Gimbel talvez despertasse mais nossa atenção se tivesse escrito "blues 'n' samba” (blues ' $n$ ' samba). O blues é conhecido por ser o alicerce do jazz, mas a bossa nova não é normalmente vista como se tivesse algo do blues. Deveria. Porque as mais famosas bossas-novas carecem da estrutura de doze compassos característica do blues clássico, assim como o formato poético das letras de uma frase inicial e repetição dessa frase, seguido de resolução em rima, a afinidade da bossa nova com o blues geralmente passa despercebida. Mas ouvindo com atenção e considerando-se a pesquisa do mundo do jazz no Rio de Janeiro no final dos anos 50 e início dos anos 60 revela-se a profunda influência do blues na explosão da bossa nova naquele mesmo período. A exploração dessa influência ajuda a iluminar a estrutura da bossa nova, expli- 
ca por que os músicos de jazz dos Estados Unidos se apegaram à bossa com tanto entusiasmo e leva em consideração algumas suposições sobre gênero existentes há muito tempo. A bossa nova sempre foi ridicularizada como uma forma de branqueamento do samba, um samba para uma elite mais sofisticada acostumada a tomar coquetéis. Mas os músicos de jazz brasileiros do fim dos anos 50 sabiam que ao incorporar as influências maiores do blues em sua música estariam entrando na fonte principal da música afro-americana. A bossa nova provou ser atraente em parte porque oferecia tanto um novo terreno emocionante para a experimentação da música como um caminho em direção às raízes de uma tradição musical afro-atlântica semelhante.

Um pequeno grupo de críticos de música ajudou a fortalecer essa atitude escrevendo sobre o jazz, blues, choro, samba e as afinidades entre eles. Seu trabalho, particularmente a publicação Revista da Música Popular de vida curta, mas influente, ajudou a dar o fim a teorias de imperialismo musical popular norte-americano, pelo menos em alguns círculos mais esclarecidos, e, em vez disso, cultivar o entusiasmo por blues, Dixieland, suingue e bebop. Esses críticos defenderam uma penca de músicos e arranjadores jovens, conhecedores dos estilos brasileiros e norte-americanos e interessados em mesclar essas influências. Embora menos conhecidos do que o triunvirato da bossa nova de Jobim, Moraes e João Gilberto, esses músicos exerceram um papel-chave na formação da bossa nova. Até certo grau significativo, entender o lugar da bossa nova na música brasileira e na música do mundo dependerá da compreensão dessa transmissão de influência e do nascimento da bossa-blues. Essa troca fértil também dá nova luz aos processos de invenção cultural no Rio de Janeiro nos anos 50. O surgimento de um número de pequenas gravadoras enraizadas na vibrante vida noturna do Rio, o curto auge da Revista da Música Popular e o interesse dos músicos brasileiros improvisadores em tradições afro-americanas estimularam uma troca de influências hemisférica. Essa influência foi atraente em parte porque agradava a compreensão entre músicos brasileiros e músicos de jazz norte-americanos que a música poderia se tornar mais moderna, em parte redescobrindo e reconsiderando as tradições do blues.

\section{A escala blues}

Tanto no Brasil como nos Estados Unidos a forte influência da África central e ocidental recombinada com práticas musicais européias produziu tradições semelhantes. Antes do século XX, ambas as nações tinham música 
popular que davam destaque a uma síncope rítmica, melisma vocal e o uso comum do violão e outros instrumentos de corda para dedilhado. Em ambas as nações, escravos africanos e seus descendentes desenvolveram práticas musicais que incorporaram uma roda de gente batendo palma e cantando, percussão, músicas sacras que incorporavam influências do ioruba e do Congo, e músicas seculares que frequentemente apresentavam um senso de humor matreiro e com duplo sentido. Nos Estados Unidos, esses ingredientes chegaram até o blues e no Brasil até o samba. ${ }^{1}$

Mas apesar das semelhanças e trocas atlânticas, os elementos básicos do blues não tinham uma presença marcante na música brasileira antes dos anos 50. As duas características mais importantes na definição do blues são o uso de doze compassos, da forma $\mathrm{AAB}$ e o uso da escala blues na construção tanto da melodia como da harmonia. Uma breve excursão à teoria básica de música esclarecerá essas características e sua relevância em relação à bossa nova. Na forma de doze compassos, as primeiras quatro medidas apresentam uma frase melódica, as seguintes quatro repetem a frase, normalmente repetindo a letra ou uma pequena variação entre elas também, e as últimas quatro finalizam a frase. Harmonicamente, essa resolução é normalmente alcançada construindo a seção A repetente de acordes dominantes com sétima baseados no primeiro e quarto graus da escala maior e a seção B numa passagem de um acorde dominante com sétima construído no quinto grau para um construído no primeiro grau. Essa forma de doze compassos não teve nada que chegasse perto na música brasileira e raramente surgiu de dentro dos confins de qualquer gênero brasileiro. As combinações de gêneros brasileiros e jazz nos anos $20 \mathrm{e}$ 40 raramente usavam a estrutura de doze compassos. A bossa nova mudou isso incorporando seções de doze compassos a estruturas mais flexíveis.

A escala blues foi uma influência bem maior. A escala maior é construída nos seguintes intervalos da nota tônica: tom inteiro, tom inteiro, meio-tom, tom inteiro, tom inteiro, tom inteiro e um meio-tom voltando à nota tônica uma oitava acima. No tom de dó, isso produz uma escala sem sustenido ou bemol, dó-ré-mi-fá-sol-lá-si-dó. A escala blues altera a escala maior removendo a segunda e sexta notas, baixando a terceira e quinta notas meio-tom e inserindo uma "nota fora" meio-tom abaixo da quinta nota. Isso produz a

\footnotetext{
${ }^{1}$ Para saber mais sobre a influência africana no blues, ver: Gerhard Kubik, Africa and the Blues (Oxford, Mississippi: University Press of Mississippi, 1999). Quanto à influência africana no samba e outros gêneros brasileiros, ver: Peter Fryer, Rhythms of Resistance: African Musical Heritage in Brazil (Middletown, Connecticut: Wesleyan University Press, 2000).
} 
seguinte progressão da nota tônica: um tom e meio ou tom aumentado, tom inteiro, meio-tom, meio-tom, tom aumentado e um tom inteiro voltando à nota tônica uma oitava acima. Ou, em dó, a seguinte escala: dó-mi bemol-Fsol bemol-sol-si bemol-dó. A terceira, quinta e sétima notas da escala maior baixam meio-tom na escala blues (embora a quinta nota em sua posição natural, sem baixar meio-tom, esteja também incluída). Essas são a terceira menor, a quinta bemolizada ou diminuta e a sétima dominante. Ou, em português, terça menor, quinta bemol, sétima dominante. ${ }^{2}$

No blues, normalmente chega-se a essas notas meio-tom abaixo de sua posição relativa na escala maior esticando uma corda de violão ou palheta de gaita-de-boca, ou através do melisma vocal, todos os quais permitem que o músico mude de uma nota para a outra microtonalmente. As melodias do blues tendem a ser construídas exclusivamente de notas na escala blues e dá grande ênfase à terceira menor, quinta bemolizada e sétima dominante essas notas são usadas para criar tensão, que é então resolvida através de um retorno à nota tônica. As variações na melodia frequentemente exageram o esticamento dessas notas para aumentar a tensão. As harmonias do blues, que contam muito com os acordes dominantes com sétima baseados no primeiro, quarto e quinto graus da escala maior, facilitam essa dependência melódica na escala blues.

A quinta bemolizada é a nota definitiva nessa escala, frequentemente descrita como "a nota fora". ${ }^{3}$ É a que soa mais dissonante em relação à escala maior e uma ênfase contínua nela desafia as regras da composição clássica ocidental. O intervalo entre a nota tônica e a quinta bemolizada são os tons inteiros, ou um trítono (o trítono é normalmente descrito como uma quarta aumentada em vez de uma quinta bemolizada, mas esses são idênticos exce-

\footnotetext{
${ }^{2}$ Musicistas podem considerar essa explicação extremamente simplista. A natureza da "nota fora”, a precisão do tom e a importância da variação microtonal dentro da escala blues, o relacionamento da escala blues à escala pentatônica e a existência de fontes africanas para a escala blues são assuntos de sério debate acadêmico. No entanto, músicos praticantes e livros de métodos musicais concordam que essas são as notas na escala blues e que outras sutilezas são preferivelmente trabalhadas em pleno agito de um show improvisado de jazz ou numa tranquila biblioteca. Essa básica compreensão da escala de blues é suficiente para entender os usos que músicos brasileiros fizeram do blues na explosão incial da bossa nova. Para debates teóricos, ver: Kubik, Africa and the Blues, e Eddie S. Meadows, Africa and the Escala blues: A Selected Review of the Literature, em Jacqueline Cogdell Djedje, ed., African Musicology: Current Trends, Vol. II (Atlanta: African Studies Association, 1992).

${ }^{3}$ Uso do termo "nota fora" é incongruente e, mais uma vez, musicistas questionam seu significado, mas é o termo mais usado normalmente.
} 
to em termos teóricos abstratos). O trítono, precisamente por causa de suas qualidades dissonantes, foi usado com moderação na música européia pelo menos a partir do princípio do Renascimento até o século XVIII, quando ele era ocasionalmente descrito como "a música do diabo". A sinceridade dessa caracterização diabólica é uma questão de debate musicológico, mas revela a cautela com a qual o trítono era tratado como um elemento de composição, uma cautela que persistiu em grande parte até o princípio do século $\mathrm{XX} .{ }^{4} \mathrm{~A}$ prevalência do trítono é parte do que tornou o blues tão obviamente diferente da música européia. Essa escala blues também abriu caminho para a improvisação do jazz.

A escala blues não foi prevalente na música brasileira antes da bossa nova. A quinta bemolizada não era de modo algum desconhecida no Brasil ela é encontrada frequentemente no baião, popularizado por Luiz Gonzaga nos anos $40 .{ }^{5} \mathrm{O}$ baião, de fato, é o gênero brasileiro mais tonalmente similar ao blues, incorporando uma abordagem semelhante ao esticamento de notas e variação microtonal. Mas as melodias do baião e as improvisações não são construídas da escala blues propriamente dita; e a escala maior é muito mais prevalente.

Nenhum outro importante gênero brasileiro recorre profundamente à escala blues ou à quinta bemolizada. Dada a extraordinária riqueza da música brasileira, é provável que um etnomusicologista possa encontrar muitos exemplos da quinta bemolizada dentro de seus domínios, mas esses seriam em grande parte fora dos estilos que chegaram a definir a música popular brasileira em sua aparência moderna, industrial nas primeiras quatro décadas do século XX. O gênero mais improvisatório, o choro, tendia a incluir a quinta bemolizada muito raramente. Os músicos de choro não usavam a escala blues como elemento básico de suas improvisações.

A bossa nova mudou isso. Mais precisamente, a onda de samba-jazz que produziu a música que se tornou conhecida como bossa nova alterou esse panorama. Na segunda metade dos anos 50, músicos do pedaço começaram a usar a escala blues como base para improvisação. Compositores e arranja-

\footnotetext{
${ }^{4}$ Um debate musicológico sobre o trítono e suas supostas afinidades diabólicas é ainda mais extenso que o debate sobre o trítono. Repetindo, essa definição reduzida apresenta o uso mais normalmente aceito. Para uma maior análise, veja o verbete "Trítono" em Stanley Sadie e John Tyrrell, The New Grove Dictionary of Music and Musicians (New York: Oxford University Press, 2003).

${ }^{5}$ Sobre o baião e suas propriedades tonais, veja Luis da Câmara Cascudo, Dicionário do Folclore Brasileiro (Rio de Janeiro: Ediouro, Terra Brasilis, 1972).
} 
dores facilitaram isso criando estruturas harmônicas que os levaram a usar a escala blues. Fazendo isso, eles buscaram modelos no jazz americano e suas bases.

\section{Jazz em Copacabana}

O mundo da música no Rio de Janeiro na segunda metade dos anos 50 estava estourando. Dezenas de novas gravadoras disputavam talentos e Copacabana estava repleta de boates, particularmente nas ruelas da Praça do Lido. Tanto as gravadoras iniciantes como as boates tocavam sem parar música produzida na zona onde o samba e o jazz se sobrepunham.

Muito da música que fizeram era de andamento rápido, apresentando improvisações instrumentais que chamavam atenção à sua própria façanha técnica-música "hot". Isso contrastava de maneiras óbvias com a abordagem "cool" desbravada em 1957 por João Gilberto, com comedimento vocal, um "suingue" suave e sem solado instrumental. Já no fim da década, o estilo de João Gilberto, particularmente suas interpretações da música de Tom Jobim e Vinicius de Moraes, já era reconhecido por ter definido um novo gênero chamado bossa nova. Muitos dos músicos em Copacabana não se viam participando nessa mesma prática e também não queriam sua música misturada nessa categoria de mercado emergente, que eles consideravam uma moda passageira. Considerando suas reservas, há uma certa tentação em rotular de bossa nova apenas a música que segue diretamente o modelo João Gilberto/ Tom Jobim/Vinicius e chamar a música de trios de piano que tocavam de improviso nos clubes de Copacabana de samba-jazz. Alguns dos músicos principais dessa leva, tal como o saxofonista J. T. Meirelles, sugeriram a mesma coisa em outras palavras.

Mas isso simplesmente trocaria generalização por imprecisão. Inventaria uma separação entre o hot e o cool, entre a batida de violão do João Gilberto e o piano animado de Tenório Jr., outro pioneiro do samba-jazz, onde nenhuma separação realmente existia. Todos os membros do triunvirato da bossa nova eram altamente familiarizados com o som dos clubes de Copacabana e todos recorriam a esse som de maneiras diferentes. Os músicos raramente conseguem dar nome aos seus próprios gêneros e a bossa nova, apesar das objeções dos pseudo-separadores, passou a descrever, corriqueiramente, todos os sons samba-jazz do final dos anos 50 e início dos anos 60, assim como a herança nacional e internacional subsequente da música do triunvirato, em particular. 
Vale ressaltar, entretanto, a variedade de abordagens subordinadas a esse rótulo, muitas das quais desapareceram gradualmente pelo menos temporariamente após a ascensão do som de João Gilberto. O musicólogo André Luis Scarabelot descreveu a fundação da bossa nova desse modo: "Podemos dizer, em princípio, que a bossa nova incorporou três pilares distintos em sua formação: João Gilberto, interpretando sambas de um jeito único, Tom Jobim, com sua experiência erudita, e os jazzistas provenientes de Copacabana". ${ }^{6}$ Desses três pilares, o terceiro foi o que recebeu menos atenção, e ele próprio abrangeu uma grande variedade de abordagens com influência do jazz.

Para começar, muitas das gravadoras mais inexperientes contratavam arranjadores e maestros populares e já estabelecidos para produzir em grande quantidade gravações próprias para dançar e, ao fazer isso, eles frequentemente incorporavam instrumentação de jazz, incluindo também padrões jazzísticos. A figura do arranjador-maestro se manteve altamente prestigiada no Brasil logo no momento em que estava desaparecendo lentamente para se reabrir no fundo do mundo da música popular norte-americana, tornando a noção de um maestro reconhecido conduzindo uma grande banda de músicos em sua maioria desacreditados através de um repertório de padrões brasileiros e norte-americanos uma solução de baixo custo de produção e altamente rentável. Todos esses maestros tiveram muita experiência em rádio brasileiro, onde eles estavam acostumados a escrever arranjos ambiciosos rapidamente, e os melhores desenvolveram seu próprio estilo.

Um típico exemplo é o Zezinho e os Copacabanas, "Um Coquetel, Uma Dança”, gravado em 1957 para a Imperial Discos. O lado A continha principalmente interpretações de padrões de samba como "Faceira" de Ary Barroso. O lado B apresentava um pout-pourri começando com "Wabash Blues". ${ }^{7}$ Nesse caso, como em outros do gênero, nem os sambas nem as melodias de jazz incluíram grande improvisação. Em sua exploração dos tons de jazz, muitos desses maestros-arranjadores buscaram inspiração na Orquestra Stan Kenton e seus arranjos frequentemente usavam tanto a estrutura de doze compassos do blues e da escala blues. Entre os praticantes principais nesse estilo, além do Zezinho, estão Léo Peracchi, Waldir Calmon, Lindolpho Gaya, Zaccarias e Luiz Arruda Paes.

${ }^{6}$ André Luis Scarabelot, Música Brasileira e Jaz:: O Outro Lado da História, Revista Digital Art\&, 3:3 de abril de 2005, acessível no site http://www.revista.art.br/site-numero-03/ trabalhos/07.htm

7 Ver http://loronix.blogspot.com/2007_07_08_archive.html, texto escrito por Loronix, 28 de junho de 2007. 
Todos esses arranjadores-maestros seguiram os passos de Radamés Gnattali, antigo orquestrador da Rádio Nacional que fez um papel pioneiro na fusão do samba com técnicas de arranjos inspirados por grandes bandas de jazz nos anos 30. Entre suas produções extraordinariamente ricas como compositor, pianista e arranjador nos anos 50 estavam um número de peças musicais curtas e sutis que exploravam os tons de jazz de saxofone de um jeito não previamente incorporado à música brasileira. Gnattali compôs sua "Brasiliana n'. 7" em 1957 especificamente para o tenor saxofonista Sandoval Dias. Dizem que Gnattali, que sempre valorizou a composição acima da improvisação, tentou compor algo que mostraria que toda aquela vivacidade, invenção e aparente espontaneidade de um solado prolongado de saxofone poderia se juntar em uma peça musical totalmente composta. O solado tenor de saxofone de Paul Gonsalves em "Diminuendo and Crescendo in Blue", com a banda de Duke Ellington em Newport, em 1956, havia criado recentemente um burburinho internacional.

A gravação ao vivo do solado de 28 refrões de Gonsalves estava rapidamente penetrando no mundo entre os feras do jazz, despertando entusiasmo pela banda de Ellington nos Estados Unidos e ajudando a criar entusiasmo para uma prolongada improvisação internacional de saxofone com base no blues. A resposta de Gnattali, numa abordagem típica de seu trabalho, pode ser ouvida como abrasileiramento e formalização desse entusiasmo.

Os três movimentos da "Brasiliana n'. 7" são todos baseados em formas brasileiras, como evidenciado por seus títulos, "Variações sobre um tema de viola", "Samba-Canção" e "Choro", mas o segundo, em particular, recorre profundamente aos tons de sax tenor de jazz. Esse era um samba-jazz marcadamente diferente do estilo que Gnattali havia criado com seus arranjos de big band do final dos anos 30 e início dos anos 40. Aqui o enfoque é intensamente na expressiva capacidade de um único instrumento, explorado minuciosamente em variações sutis em um curto tema. Ao ser executada com um toque jazzístico, a peça soa como uma improvisação, mas cada nota é perfeita composicionalmente. ${ }^{8}$

Dois anos depois, Gnattali levou sua trajetória mais adiante, gravando um álbum de suas próprias obras mais curtas, apresentando Paulo Moura no saxofone alto, acompanhado pelo próprio Gnattali no piano, um jovem Baden

${ }^{8}$ Ver, por exemplo, a gravação recente de Leo Gandelman, em Leo Gandelman, Radamés e o Sax, Biscoito Fino, 2007. 
Powell na guitarra elétrica e uma seção de ritmo de tambores e baixo. Em todo o álbum - Paulo Moura Interpreta Radamés Gnattali - Paulo Moura adota um tom bluesístico, ligando e esticando as notas, deslizando suavemente com os ritmos variados. Como foi dito antes, as peças soam como improvisações de jazz; particularmente no samba-canção "Sempre a Sonhar" e a balada "Devaneio", que fecha com um riff de blues. Isso está muito distante tanto do concerto de saxofone europeu e o tipo de sax choro tocado nos mesmos anos por Pixinguinha. ${ }^{9}$

Mais parecido com esse estilo de composição era o tocador de clarinete e sax K-Ximbinho (Sebastião de Barros). K-Ximbinho era principalmente um músico e compositor de choro, mas suas composições e gravações dos anos 50 revelavam uma crescente influência de jazz e blues. Seu LP Ritmo e Melodia até incluiu uma interpretação de "Rock Around the Clock", demonstrando que ele tinha um entusiasmo mais que contido para inovações baseadas no blues. K-Ximbinho era bem conhecido como um dos mais bem-sucedidos jazzistas no cenário carioca, e suas composições incorporavam uma forte influência do jazz e do blues. Sua composição "Ternura", por exemplo, lembra o blues de Thelonious Monk "Round Midnight" no fraseado, assim como outros blues de Monk como "Straight no Chaser" e "Blue Monk" em suas linhas cromáticas ascendentes. As aventuras de K-Ximbinho nesse estilo exerceram grande influência em jovens colaboradores e fãs como Moura e J. T. Meirelles.

Os estilos musicais de saguão de vocalistas como Dick Farney e Lúcio Alves tiveram um efeito direto maior nos jovens músicos que viriam a definir a bossa nova. Farney e Alves, ambos profundamente influenciados por Frank Sinatra, favoreciam pequenos grupos como seus grupos de apoio, apresentando piano, baixo, bateria e ocasionalmente trombone, trompete e saxofone. Esses foram basicamente grupos de jazz, igualmente capazes de interpretações suingadas de músicas populares bem conhecidas, como "All of Me", e de sambas como "Beija-me". De fato, os músicos desse grupo - incluindo o próprio Farney, um talentoso pianista de jazz e crooner-orgulhavam-se de demonstrar seus talentos variando de um para o outro sem nenhum esforço. Seus shows em clubes noturnos dependiam precisamente dessa tática de mudar tons e ritmos sem que ninguém esperasse.

\footnotetext{
${ }_{9}^{9}$ Para uma maior análise da abordagem de Radamés Gnattali ao saxofone, ver Marco Túlio de Paula Pinto, O Saxofone na Música de Radamés Gnattali, ANPPOM, Décimo-Quinto Congresso, 2005.
} 


\section{Pittman e companhia}

Quem ensinou esses jovens músicos a tocar o blues? Eles aprenderam muito ouvindo disco, claro. Mas eles também encontraram alguns músicos com vasta experiência que lhes ensinaram as sutilezas e possibilidades do gênero. Em primeiro lugar, entre eles estava o saxista e clarinetista Booker Pittman, um músico de ótimo pedigree para a transmissão da cultura afroamericana. Booker Pittman foi o neto de Booker T. Washington, criado desde bebê com a música afro-americana e seu contexto político e histórico. A filha de Washington, Portia, foi uma aspirante pianista de concerto, treinada em conservatórios de música na Nova Inglaterra e Berlim. Portia se casou com um arquiteto formado na universidade de Tuskegee chamado William Sidney Pittman, e o casal deu o nome ao segundo filho, nascido em 1909, de Booker. Eles viveram por um curto período em Washington, D.C., e depois passaram a maior parte da infância de Booker em Dallas, onde Portia ensinava piano e Sidney Pittman exercia sua profissão como arquiteto. Portia retornou a Tuskegee no final dos anos 20, mas naquela época seu filho já estava fazendo turnês e trabalhando como músico de jazz. ${ }^{10}$

Booker Pittman viajou com uma série de big bands na América do Sul no final dos anos 20 e início dos anos 30, tocando clarinete e sax alto e soprano. Em 1933, dizem que ele chegou à França com a big band de Lucky Millinder. Na França, Pittman se sentou com Jazz Band Sul-Americano, uma big band liderada pelo empreendedor saxofonista brasileiro Romeu Silva, que havia criado inicialmente a banda no Rio em 1923. Pittman se juntou à banda Silva ao retornar ao Brasil em 1935, tocando no Cassino Atlântico do Rio na maior parte daquele ano. ${ }^{11}$

A biografia de Pittman dos últimos vinte anos é menos fácil de montar. Ele fez umas poucas gravações na Argentina no início dos anos 40 sob o nome de Booker Pittman's Boys. Mas parece que ele passou a maior parte do período no Brasil, trabalhando intermitentemente como músico, mas longe da notoriedade. Além de sofrer de tuberculose, complicada pelo grande consumo de álcool, cocaína e maconha, ele praticamente sumiu da opinião pública e duas vezes foi dado como morto pelos jornais brasileiros. No início dos anos

\footnotetext{
${ }^{10}$ Ross Stewart, Portia: The Life of Portia Washington Pittman, the Daughter of Booker T. Washington. (New York: Doubleday, 1977).

${ }^{11}$ Para informação sobre as viagens de Romeu Silva, ver Daniella Thompson, The Globetrotting Romeu Silva, acessível em http://daniellathompson.com/Texts/Investigations/Romeu Silva.htm, um website imperdível sobre a música brasileira, Musica Brasiliensis.
} 
50 ressurgiu no Paraná, tocando blues e boogie-woogie em clubes ilegais de jogos de azar em Londrina e cidades vizinhas. Segundo ele mesmo, bebia quatro ou cinco doses de cachaça entre cada set, uma prática que talvez ajude a explicar sua inconsistência. ${ }^{12}$

No final de 1956, Booker retornou ao Rio de Janeiro, aparentemente com a ajuda do jornalista Sérgio Porto e outros fãs cariocas bem conectados que haviam ouvido falar de suas aventuras no Paraná. Pittman, um jazzista afro-americano bem viajado, beberrão, com uma conexão direta à Dixieland, ao som do blues e jazz polifônico do sul da América, rapidamente se tornou um favorito no mundo vibrante do jazz de meados dos anos 50. Os críticos de jazz da Revista da Música Popular, incluindo Porto, defenderam a chegada de Booker ao Rio como o retorno de um ícone.

O tio de Porto, o crítico Lúcio Rangel, fundara a revista alguns meses antes e já conseguira garantir a fama de publicação mais séria do jornalismo musical. Em contraste com outras publicações-estrelas, como a Revista do Rádio e Radiolândia, a Revista da Música Brasileira apresentava poucas fotos, quase nada sobre a vida pessoal das pessoas em destaque e poucas propagandas. Em vez disso, ela continha artigos detalhados de 5 mil palavras com títulos como "Antologia da música brasileira" e "Seleta discografia do jazz tradicional". A revista continha descrições sobre importantes fundadores nas tradições tanto brasileiras como norte-americanas, tais como Ismael Silva e Fats Waller. Mas também incluía notas sobre quem estava tocando em Copacabana, assim como quem havia tocado recentemente na Birdland em Nova York. Resumindo, a revista era uma detalhada pesquisa crítica do atual estado da música popular brasileira e norte-americana num contexto histórico. ${ }^{13}$

Porto e outros contribuintes da revista, incluindo Guinle, socialite e patrocinador de jazz, enalteciam Pittman. Como um artigo na Revista da Música Popular colocou, "Ouvir o Sr. Pittman improvisar num tema de blues era, verdadeiramente, algo inesquecível pela riqueza de imaginação e força

${ }^{12}$ Ophelia Pittman, Por Você, Por Mim, Por Nós, Rio de Janeiro: Editora Record, 1984, p. 139. A biografia de Ophelia Pittman inclui material abundante escrito na voz do falecido marido Booker, muito da qual foi extraído de cartas e outros rascunhos deixados por Booker Pittman. Parcialmente porque parte desse material foi parafraseado, e principalmente porque as próprias memórias de Booker Pittman dos anos entre 1940 e 1956 foram compreensivelmente obscuras, esses trechos não podem ser considerados totalmente fidedignos.

${ }^{13}$ Coleção Revista da Música Popular, Edição Fac-similada (Rio de Janeiro: Funarte, Bem-tevi Editora, 2006). 
criativa". ${ }^{14} \mathrm{O}$ próprio Rangel celebrou o retorno de Pittman com um artigo efusivo na revista Senhor, onde ele declarou que o talento de Pittman no sax soprano era superado somente pelo de Sidney Bechet. ${ }^{15}$ Porto e Guinle ajudaram a reintroduzir Pittman no mundo musical do Rio e, em particular, a uma promissora geração de ambiciosas feras do jazz. Pittman montou sua própria banda e começou a tocar em clubes de Copacabana e outros lugares.

Uma gravação de 1960 de um show num espaço de São Paulo captura o sentimento dessas performances. A gravação consiste de dois sets, o primeiro apresentando Dick Farney como pianista-líder de um pequeno grupo, tocando padrões de jazz com mudanças de bebop e improvisações. O segundo set apresenta Pittman liderando um grupo diferente, tocando saxofone e ocasionalmente cantando, utilizando antigos padrões jazzísticos como "Tiger Rat", "St. Louis Blues" e "Sweet Georgia Brown". O som de Pittman é infecciosamente bem-humorado, fluente e empático, e sempre altamente baseado na escala blues. Seu desempenho vocal é teatral e aparentemente improvisado, para o aparente deleite do público. A performance é como se fosse uma rápida aula de mestre em improvisação do blues, polifonia e espetáculo de jazz de Nova Orleans..$^{16}$

Pittman foi um dos primeiros jazzistas nascidos nos Estados Unidos a misturar jazz improvisado com a batida de violão estilo João Gilberto. Honrando essa contribuição, Vinicius de Moraes incluiu Booker Pittman na lista de músicos para quem ele conferiu bênçãos em seu discurso monólogo durante sua interpretação de "Samba da Bênção", estreada no show O Encontro no clube noturno Au Bon Gourmet, em agosto de 1962.. ${ }^{17}$

Em 1963, Pittman e sua enteada, Eliana Pittman, gravaram um álbum intitulado News from Brazil, incluindo padrões do novo gênero, como "O Barquinho" e "Nós e o Mar", o padrão de jazz de Duke Ellington "It Don't Mean a Thing" e um suingue animado intitulado "Mister Bossa Nova", perfeito para o estilo improvisador de Booker. Booker e Eliana se juntaram ao Tamba Trio, apresentando Luiz Eça no piano, Bebeto na flauta e baixo, e Hélcio Milito na bateria - uma combinação de uma bossa inspiradora formada por membros

${ }^{14}$ Autor desconhecido, "O Muito Vivo Mr. Booker Pitman” (sic), Revista da Música Popular, 1:5, Fevereiro, 1959, p. 38-39. O artigo foi provavelmente escrito por Sérgio Porto.

${ }^{15}$ Lúcio Rangel, "Booker Pittman, Um Músico de Jazz”, Senhor, Julho, 1959, reproduzido em Sérgio Augusto, Lúcio Rangel: Samba, Jazz $\mathfrak{G}$ outras notas (Rio de Janeiro: Editora Agir, 2007, p. 199-205).

${ }^{16}$ Booker Pittman e Dick Farney, Jam Session das Folhas, RGE, 1961.

${ }^{17} \mathrm{http}: / /$ daniellathompson.com/Texts/Reviews/Bon_Gourmet.htm 
da geração mais jovem de músicos cariocas influenciados por Pittman no final dos anos 50. A gravação é, no entanto, uma das jóias do início dos anos 60 por sua entusiasmada hibridez e pela revelação de Eliana Pittman, que viraria uma famosa cantora de samba-soul no final da década. A gravação de 1963 também documenta Eliana como uma das primeiras cantoras a fazer um scat em bossa nova, uma distinção que ela divide com Leny Andrade e Elza Soares. O que não é de se surpreender é que sua improvisação vocal segue o modelo bluesístico de seu padrasto. ${ }^{18}$

Músicos cariocas estavam certamente familiarizados com a improvisação bluesística antes do retorno de Pittman ao Rio e até já haviam ouvido esse método aplicado a elementos brasileiros através das gravações de Bud Shank/ Laurindo Almeida de 1953. O LP de Almeida e Shank, Brazilliance, gravado em Los Angeles em 1953, já vem há tempos sendo reconhecido como o precursor da bossa nova. Os estilos de violão de Almeida pressagiaram a abordagem mais atraente de João Gilberto alguns anos depois. E o toque com palheta descontraído de Shank característico da costa oeste americana estabeleceu um modelo para a interpretação de Stan Getz das composições de Tom Jobim no início dos anos 60. Brazilliance inclui uma melodia intitulada "Blue Baião", que torna explícita a similaridade de "Terra Seca" de Ary Barroso. ${ }^{19}$ A colaboração Almeida-Shank é um marco, mas em meados dos anos 50 era menos influente entre os músicos do Rio do que o retorno de Booker Pittman.

Os músicos cariocas estavam também ligadíssimos nas últimas gravações de estrelas como Nat King Cole. Alfredo José da Silva, já conhecido como Johnny Alf lá pelos meados dos anos 50, era um protótipo da juventude voltada para o jazz. A canção "Chega de Saudade" de Ruy Castro captura a importância do fã-clube de Farney-Sinatra, um clube do início dos anos 50 organizado por um grupo de adolescentes no bairro da Tijuca do Rio de Janeiro para celebrar a música de seus dois ídolos. Como Castro mostra em detalhe, o Clube FarneySinatra se tornou um ponto de encontro para muitos dos músicos que criariam a bossa nova mais no final da década, incluindo João Donato, Paulo Moura, Dóris Monteiro e o jovem pianista Johnny Alf. ${ }^{20}$ No meio da década, Alf estava mais voltado para Cole e George Shearing do que Farney e Sinatra, e essas influências começaram a emergir através de sua música. No final da década,

\footnotetext{
${ }^{18}$ Booker Pittman e Eliana Pittman, News From Brazil, Odeon, 1963.

${ }^{19}$ Bud Shank e Laurindo Almeida, Brazilliance, Nota fora, 1953.

${ }^{20}$ Ruy Castro, Chega de Saudade: A História e as Histórias de Bossa Nova (Companhia das Letras, 1990, p. 31-45).
} 
Alf estava escrevendo músicas que eram uma mescla de samba, tons de jazz e harmonias ambiciosas. Em suas mais conhecidas composições, incluindo padrões de bossa nova como "Rapaz de Bem" e "Eu e a Brisa", usa a quinta bemolizada em estruturas musicais de jazz complexas para criar dissonância e tensão. A elegância melancólica e seu uso ocasional mas decisivo de notas foras são extraordinariamente semelhantes aos de seus modelos Cole e Shearing, e exerceram grande influência no público inicial da bossa nova.

Quem se juntou a Pittman e Alf na vanguarda da hibridez do samba-jazz foi o saxofonista Moacir Santos, um músico com uma grande familiaridade com gêneros brasileiros, um conhecimento avançado teórico de harmonia e uma paixão pelo jazz. Santos nasceu em Pernambuco e na adolescência havia trabalhado por pouco tempo como músico itinerante no sertão de Pernambuco. Ele chegou ao Rio nos anos 40, onde sua extraordinária habilidade e sua versatilidade o levaram a se integrar à prestigiosa orquestra da Rádio Nacional. Ele também estudou com Hans-Joachim Koellreutter, uma das figuras dos bastidores no surgimento da bossa nova. Koellreutter, compositor alemão que havia se estabelecido no Rio de Janeiro, foi um professor de harmonia inspirador e desafiador, que acreditava que o treinamento rigoroso em harmonia avançada permitiria que seus alunos descobrissem seu próprio som, que poderia recorrer profundamente a fontes populares e também eruditas. Koellreutter treinou o jovem Jobim no início dos anos 40, o que serviu como alicerce para a bossa nova. E treinar Santos - assim como Paulo Moura e vários outros músicos inovadores do final dos anos 50 - produziu uma série variada de aventuras musicais. $\mathrm{O}$ trabalho de Santos como compositor, arranjador e solista de sax alto no início dos anos 60 criou novos híbridos de tons de blues e ritmos brasileiros.

\section{"Blues Walk"}

No início dos anos 60, os músicos que improvisavam com Pittman, Moura, Santos e Alf, e aprendiam suas manhas, não só melhoravam seu próprio som, mas seu próprio repertório, que incluía as famosas bossas-novas que estavam se tornando sucessos internacionais, como "Só Danço Samba", mas também incluíam melodias de jazz e blues que se tornaram padrões em Copacabana.

"Blues Walk", um blues de doze compassos pelo trompetista de jazz Clifford Brown, é um excelente exemplo. Sua melodia é típica dos "cabeças" do blues aprendida por músicos de jazz como um trampolim para improvisa- 
ção - simples, atraente e contendo uma idéia melódica básica que pode ser retrabalhada dentro da escala blues em várias maneiras diferentes. Os grupos de Copacabana tocaram "Blues Walk" milhares de vezes no início dos anos 60 e a gravaram frequentemente.

Em 1963, o Bossa Três, um trio de Copacabana prototípico com Luis Carlos Vinhas no piano, Edison Machado na bateria e Tião Neto no baixo, gravou uma versão suingue de samba-jazz. Neto toca um solado de linha de baixo, enquanto Machado toca um padrão de jazz com adornos sambistas e Vinhas improvisa baseado na escala blues. Quando faz o solado, Machado muda para um padrão de samba e depois sai para permitir uma troca de frases entre Neto e Vinhas até o trio reconectar para fechar a melodia. ${ }^{21}$ A performance é típica da hibridez improvisada do samba e blues comuns no circuito de Copacabana.

Dada a popularidade de "Blues Walk" nos círculos da bossa nova, não é surpreendente que compositores brasileiros começassem a escrever seu próprio blues de doze compassos. A canção "Blue Bottle's” de Meirelles, de 1964, escrita em homenagem ao clube noturno de Copacabana Bottle's, e "Samblues", por Maurício Einhorn e Durval Ferreira, eram ambos blues de doze compassos usados como plataformas para improvisação de jazz no ritmo de samba. Como "Blues Walk", essas outras canções eram padrões em Copacabana. ${ }^{22}$

\section{Lyra eJobim}

O subgênero emergente da bossa-blues se mostrou influente mesmo entre compositores mais firmemente associados com o som "clássico" da bossa nova, como Carlos Lyra e o próprio Jobim. Talvez isso seja levemente surpreendente com relação a Lyra, que no início dos anos 60 foi fundador e participante-chave no Centro Popular de Cultura da União Nacional dos Estudantes, o tão conhecido CPC da UNE. O CPC adotou uma visão de cultura popular nacional informado por uma leitura estrita de teoria cultural marxista e olhou com desconfiança a influência cultural internacional e as demandas do mercado. ${ }^{23}$ A clara dívida da bossa nova ao jazz provocou considerável ansiedade dentro do CPC. A "Influência do Jazz" de Lyra de 1961 expressava essa ansie-

${ }^{21}$ Bossa Três, Os Bossa Três, Audio Fidelity, 1963.

${ }^{22}$ Para um exemplo excelente, ver o Sambalanço Trio, Sambalanço Trio, Som Maior, 1965.

${ }^{23}$ Para detalhes sobre o Centro Popular de Cultura (CPC), ver: Jalusa Barcelos, CPC da UNE: uma história de paixão e consciência (Rio de Janeiro: Nova Fronteira, 1994). 
dade e parecia ridicularizá-la ao mesmo tempo - a letra dessa música lamenta que "o pobre samba meu" se misturou ao jazz e a gêneros afro-cubanos, mas a melodia revela a influência de ambos no suingue de jazz, durante o verso, e rumba cubana, no refrão. Portanto, a letra de "Influência do Jazz" tem um ar de letra de alguém que protesta demais contra uma paixão que ele negaria. É impossível determinar se Lyra estava sendo sarcástico quando compôs essa canção, ou se sua ironia é desintencional. Independentemente da intenção inicial de Lyra, um ano após compor "Influência do Jazz", ele compôs outro clássico da bossa nova que carregava uma influência norte-americana ainda mais pronunciada.

Em 1962, Lyra se juntou com Vinicius de Moraes para escrever "Pobre Menina Rica", um musical romântico sobre um migrante empobrecido que vive numa favela e se apaixona por uma menina rica da cidade. A peça segue rigorosamente a pauta do CPC sobre a exploração da classe operária. Uma de suas mais memoráveis composições é uma bossa-blues intitulada "Maria Moita”, narrada por uma personagem de mesmo nome, companheira do líder das favelas. "Maria Moita" não é um blues de doze compassos, embora suas repetidas células melódicas, levando a uma crescente tensão e resolução, sejam muito semelhantes a uma estrutura padrão de blues. A influência é mais clara na melodia, rica em terceiras menores, quintas bemolizadas e sétimas dominantes. A estrutura sutil e harmônica de Lyra, típica da melhor bossa nova, apresenta mudanças de acorde sofisticadas de maneira acessível e flexível, permitindo que intérpretes conduzam a composição para qualquer direção das várias possíveis.

O Trio Bossa Jazz, outro grupo de Copacabana, com Amylson Godoy no piano, Jurandir Meirelles no baixo e José Roberto Sarsano na bateria, escolheu dar ênfase na influência do blues. Numa gravação de 1965 eles tocaram "Maria Moita" como um blues melancólico balançado, sem nenhum gesto óbvio de fidelidade rítmica ao Brasil. Eles levaram a obra de Lyra para longe da utopia nacionalista do CPC, para dentro das entranhas do mundo dos clubes de Copacabana. ${ }^{24}$

Ao contrário dos jornalistas da Revista da Música Popular, que viam o blues como uma autêntica expressão da cultura afro-americana, enobrecida através de séculos de sofrimento, Lyra aparentemente não considerou o blues tão análogo com o samba, nem uma fonte de matéria consciente para uma

${ }^{24}$ Bossa Jazz Trio, Bossa Jazz Trio, Som Maior, 1965. 
produção CPC. A influência do blues de "Maria Moita" pode ter sido totalmente desintencional. Aluno sofisticado de harmonia clássica ocidental, Lyra era profundamente familiarizado com a mística do trítono, incluindo tanto a sua condenação durante o Renascimento e seu uso para criar dissonância produtiva desde o final do século XVIII. De acordo com Lyra, quando Jobim estava compondo "Amor em Paz", ele e Jobim brincavam com a harmonia, propositalmente incluindo acordes com quintas bemolizadas e sétimas dominantes, precisamente porque ela desafiava as regras da composição ortodoxa. Esse trabalho em conjunto não era incomum, nem seu resultado: Jobim fez o arranjo da música para a produção original de "Pobre Menina Rica" e usou o mesmo método. De acordo com Lyra, Jobim incluiu quintas bemolizadas no arranjo para as canções de Lyra "Samba do Carioca" e "Primavera", brincando com Lyra que isso era considerado "o intervalo do diabo" e que eles poderiam ser excomungados. ${ }^{25}$

Essas histórias sugerem que ambos os compositores eram atraídos pela quinta bemolizada como uma ferramenta para dissonância criativa principalmente através de sua familiaridade com a música erudita. Mas eram também altamente ligados à música que acontecia em torno deles em Copacabana. Eles notaram, por exemplo, que Sérgio Mendes - apenas um adolescente, mas já um talento brotando no mundo da bossa nova - também era fã das quintas bemolizadas e sétimas dominantes. Mendes, ao contrário de seus colegas mais experientes, foi mais diretamente influenciado pelo jazz, particularmente o som baseado no blues de estalar os dedos de Horace Silver, o ídolo de Mendes. Duas tradições - o clássico ocidental e o blues - estavam convergindo em Copacabana para fazer com que a quinta bemolizada se tornasse mais e mais popular.

Essas histórias começam a mostrar a circularidade de influência no campo. Jobim foi claramente a maior influência de Lyra, mas Jobim era também aberto à influência do Lyra. Talvez não seja surpreendente, na época, que não muito depois que Lyra compôs "Maria Moita", Jobim compôs uma melodia semelhante. Como "Maria Moita", a canção "O Morro Não Tem Vez" de Jobim - novamente, com letra por Vinicius de Moraes - é uma bossablues com uma linha melódica que sobe através da escala blues em células repetidas, alcançando um ponto máximo dissonante e depois encontrando a

${ }^{25}$ Luiz Roberto Oliveira, entrevista com Carlos Lyra, 1996, website do Clube do Tom, acessível em http://www.jobim.com.br/clyra/lyra3.html 
solução. Nesse caso, Lyra alega ter convencido Jobim a alterar a composição precisamente para torná-la menos bluesística: "Teve uma vez também que eu sugeri que ele mudasse uma nota em 'O Morro Não Tem Vez'. Sua frase melódica estava mais próxima do blues e ele acabou usando o que eu lhe mostrei e disse, 'Isso é mais perto de algo do povo, do morro, não mais algo que vem de um morro qualquer dos Estados Unidos ou de algum negócio de Beverly Hills; esse morro é mais carioca'". ${ }^{26}$

Essa afirmação, extraída de uma entrevista de 1996, talvez esteja levemente distorcida pelo tempo. O diálogo atribuído aqui ao Jobim parece mais de acordo com a compreensão do CPC da influência musical estrangeira do que a de Jobim. De qualquer maneira, é totalmente plausível que Lyra tenha sugerido uma alteração em "O Morro Não Tem Vez", e que Jobim tenha concordado. Caso positivo, e se o efeito era dar à composição um ar menos bluesístico, a alteração seria mais do que possível ser uma mudança de um B natural para um C natural para a sílaba "der" na linha "Quando derem vez", ou transformar um E bemolizado em um E natural na sílaba "ao", na frase "ao morro todo o morro". No primeiro caso, isso significaria mudar uma terceira menor para uma terceira maior numa seção da composição em A menor. No segundo caso, significaria mudar a quinta bemolizada para uma quinta maior.

Enquanto, por um lado, isso é fascinante para os viciados em bossa nova, por outro, não teve nenhum efeito significativo na influência do blues em "O Morro Não Tem Vez". A ponte da melodia, que muda para D menor, divide uma afinidade ainda mais óbvia com o blues, não menos na quinta bemolizada na sílaba "tam” em "tamborim vai falar". O que quer que Jobim e/ou Lyra pretendessem, inúmeros músicos enfatizaram as possibilidades bluesísticas na composição. Para um exemplo particularmente polido, ver versão de Hélio Delmiro de seu CD Compassos. Delmiro leva a afinidade além, substituindo muitos dos acordes de Jobim com acordes arraigados na quinta bemolizada do acorde original - uma prática comum de jazz conhecida como substituição de trítono - dessa forma tornando o trítono uma presença mais enfática na melodia. Além de suas alterações harmônicas, a guitarra elétrica de Delmiro floresce e as improvisações são firmemente arraigadas numa tradição blues-jazz. ${ }^{27}$

\footnotetext{
${ }^{26}$ Oliveira, entrevista com Carlos Lyra, Clube do Tom.

${ }^{27}$ Hélio Delmiro, Compassos, Deckdisc, 2004.
} 


\section{O outro lado da moeda}

Não surpreendentemente, jazzistas dos Estados Unidos pegaram essa afinidade com o blues e fugiram com ela. As gravações de bossa nova de Cannonball Adderley e Herbie Mann de 1962 e 1963 tinham blues em abundância. Herbie Mann até gravou uma versão bossa nova de "Blues Walk" com Sérgio Mendes no início dos anos 60. Os guitarristas Charlie Byrd, Joe Pass e Barnie Kessel tinham em comum essa antiga ligação à bossa nova, mais em conformidade com Adderley e Mann na incorporação de um vocabulário com base bluesística. Isso não era surpreendente - esses músicos essencialmente tocavam bossa nova do mesmo estilo que seus colegas brasileiros já estavam tocando. Para ter certeza, eles recorreram a muitos recursos - Mann tende para um estilo modal de tocar crescentemente comum nos círculos de jazz no início dos anos 60, por exemplo. Mas a natureza de sua abordagem improvisatória não é radicalmente diferente das dos músicos de Copacabana.

Mais chocante talvez seja a vivacidade com a qual jazzistas americanos começaram a compor bossa nova. O exemplo mais conhecido é Horace Silver, e isso pode ter tido algo a ver com a maneira com que ele foi criado: o pai de Silver, João Tavares Silva, era um cabo-verdiano que imigrou em Connecticut. O nome de batismo de Silver era Horace Ward Martin Tavares da Silva, mas se seu pai tivesse convencido sua mãe afro-americana a retornar com ele a Cabo Verde, ele talvez tivesse ficado conhecido como Horácio da Silva. Mesmo crescendo em Norwalk, Connecticut, Silver foi exposto à música do triângulo luso-atlântico desde o início, através de seu pai, um músico amador. Tavares da Silva havia saído de Cabo Verde em 1898, mas mesmo antes da ascensão da música gravada, estilos cabo-verdianos eram muito semelhantes aos do Brasil; e partituras e os próprios músicos brasileiros circulavam pelo arquipélago cabo-verdiano. Isso ajuda a explicar por que Silver percebeu uma ressonância paterna no samba. ${ }^{28}$

Visitar o Rio de Janeiro no início dos anos 60 - onde ele e Sérgio Mendes ficaram e fizeram shows improvisados em Copacabana - permitiu que Silver alcançasse maior sucesso em sua próxima tentativa. Sua composição "Canção Para Meu Pai”, de 1965, foi uma das paradas de sucesso do ano, e sem dúvida a mais atraente bossa-blues composta por um jazzista americano. Típico do trabalho de Silver, tanto a melodia como a improvisação dele na gravação

${ }^{28}$ Para detalhes sobre os primeiros anos de vida de Silver e sua viagem ao Brasil, ver Horace Silver, Let's Get to the Nitty Gritty (Berkeley, University of California Press, 2006). 
original são profundamente cravadas no blues. ${ }^{29}$ Silver seguiu o sucesso de "Song For My Father" com várias outras tentativas no mesmo estilo, incluindo a contagiante "Cape Verde Blues". Mais do que outro músico de jazz, Silver ajudou a fazer com que a improvisação com base no blues fosse o primeiro recurso de muitos jazzistas que confrontavam a bossa nova.

Isso ajuda a explicar a reação do saxofonista Lee Konitz à composição "Wave" de Jobim. De acordo com o grande gaitista Toots Thielemans, Konitz uma vez lhe disse: “Toots, nós já tocamos 'Wave' há quarenta anos. São dois refrões de blues soltando um bebop" ${ }^{30}$ Novamente, o fato de Jobim ter recorrido ao blues na primeira sessão de doze compassos de "Wave" pode ter sido desintencional. Mas músicos bem versados na linguagem, tanto brasileira como norte-americana, logo perceberam isso desse jeito e tocaram adequadamente.

O quinto ano de aniversário do surgimento da bossa nova - significando, claro, a gravação de João Gilberto de "Chega de Saudade" em 1958 - trouxe uma série de retrospectivas e reconsiderações do gênero. Justificadamente, a maior parte da atenção era enfocada nas obras-primas do triunvirato representado naquela gravação icônica - João, Tom e Vinicius. Mas o rico contexto para o surgimento e crescimento inicial da bossa nova, incluindo suas conexões com o blues, é atualmente mais acessível para reinterpretação do que em qualquer época nos últimos cinqüenta anos. O crescimento dos sites como loronix.com, especializado em digitalização e disseminação de gravações brasileiras raras da era da bossa nova, oferece uma perspectiva panorâmica na variedade do mundo de Copacabana dos anos 50 pela primeira vez. Os primeiros selos da época normalmente imprimiam mil ou duas mil cópias por gravação, vendidas o maior número possível no menor espaço de tempo, sem nunca olhar para trás. O crescimento de fóruns da Internet dirigidos por colecionadores e fãs para compartilhar essas gravações esgotadas torna possível escutar uma extraordinária gama de combinações de samba e jazz disponíveis no Rio de Janeiro no curto auge dos inferninhos.

\footnotetext{
${ }^{29}$ Horace Silver, Song For My Father, Nota fora, 1965.

${ }^{30}$ Jazz Times, March 2007, "Before and After" - teste de olhos vendados com Toots Thielemans, administrado por Larry Appelbaum. Vale notar que Thielemans lembrou dessa observação enquanto ouvia uma gravação de Stevie Wonder tocando um pout-pourri do Vinicius de Moraes/Baden Powell, "afro-sambas" "Berimbau" e "Consolação". Pode-se considerar os "afro-sambas", com base quase que totalmente nos acordes com sétima menor que convidam a um uso improvisatório da escala blues, manifestações particularmente fortes da sensibilidade da bossa-blues.
} 
A publicação de uma edição fac-similada de uma tiragem completa da Revista da Música Popular por Funarte e Bem-te-vi Editora em 2007 é apenas igualmente decisiva a essa reconsideração. ${ }^{31}$ Uma revista que estava disponível somente em algumas bibliotecas e coleções por décadas a fio é atualmente relativamente fácil de consultar. Suas páginas de revisões de jazz e debates sobre a história do blues revelam quão presentes esses assuntos estavam nas mentes da clientela mais assídua dos clubes noturnos de Copacabana nos anos logo antes do boom, ou rápida expansão, da bossa nova, e mostram que uma reverência por tradição poderia facilmente coexistir com um entusiasmo por inovação e hibridez transnacional.

Também de tamanha importância eram os artigos na Revista da Música Popular, particularmente os escritos por Porto, Guinle e Rangel, que demonstravam que os contribuintes estavam interessados nesses produtos da hibridez transnacional em grande parte porque eles eram fascinantes pelas profundas tradições da música afro-americana. Essa fascinação ajuda a explicar o entusiasmo com o qual eles defenderam o retorno de Booker Pittman, e facilitaram essa interação com a geração mais nova de músicos cariocas. Essa interação propriamente dita era icônica - um exemplo crucial entre muitas das novas conexões forjadas no final dos anos 50 entre músicos brasileiros e o blues. Como o próprio Vinicius expressou em seu show legendário no Au Bon Gourmet, "A bênção, Booker Pittman".

${ }^{31}$ Coleção Revista da Música Popular, Edição Fac-similada (Rio de Janeiro: Funarte, Bem-tevi Editora, 2006). 